\title{
Effect of heptavalent pneumococcal conjugate vaccination on invasive pneumococcal disease in preterm born infants
}

\author{
Simon Rückinger ${ }^{1 *}$, Mark van der Linden ${ }^{2}$, Rüdiger von Kries ${ }^{1}$
}

\begin{abstract}
Background: Evidence for protection of preterm born infants from invasive pneumococcal disease (IPD) by 7valent pneumococcal conjugate vaccination (PCV7) is relatively sparse. Data from randomized trials is based on relatively small numbers of preterm born children.

Methods: We report data from active prospective surveillance of IPD in children in Germany. The cohorts of preterm born children in 2000 and 2007 and the respective whole birth cohorts are compared regarding occurrence of IPD.

Results: After introduction of PCV7 we observed a reduction in the rate of IPD in preterm born infants comparing the 2000 and 2007 birth cohort. The rate of IPD among the whole birth cohorts was reduced from 15.0 to 8.5 notifications per 100,000 ( $P<.001)$. The impact among the preterm birth cohort was comparable: A reduction in notification rate from 26.1 to 16.7 per 100,000 comparing the 2000 with the 2007 preterm birth cohort $(P=.39)$. Preterm born infants with IPD were either unvaccinated or vaccinated delayed or incomplete.
\end{abstract}

Conclusions: This adds to evidence that PCV7 also protects preterm born infants effectively from IPD. Preterm born infants should receive pneumococcal vaccination according to their chronological age.

\section{Background}

Streptococcus pneumoniae is a major source of morbidity and mortality worldwide. It is estimated that S. pneumoniae causes around $11 \%$ of all deaths in children aged 1-59 months [1]. Invasive pneumococcal disease (IPD) in children is associated with considerable casefatality rates and rates of sequelae, even in industrialized countries [2-6]. In February 2000, a 7-valent pneumococcal conjugate vaccine (PCV7) was licensed in the US. This vaccine offers the possibility for a general vaccination program in infants and toddlers. Starting from 2001, a strong decrease of IPD incidence in children has been reported from the US [7-11]. Several European countries have shown decreases in the incidence of IPD after introduction of PCV7 [12] including Germany [13].

Preterm born infants are at higher risk for infectious diseases like invasive pneumococcal disease (IPD), with

\footnotetext{
* Correspondence: simon.rueckinger@med.uni-muenchen.de

'Ludwig-Maximilians-University of Munich, Institute of Social Pediatrics and Adolescent Medicine, Division of Epidemiology, Germany
}

the highest risk in early infancy [14]. Vaccination of preterm born infants is often performed delayed [15]. Efficacy of heptavalent pneumococcal conjugate vaccination (PCV7) to protect infants younger than 2 years from IPD was shown in a randomized controlled trial [16]. Evidence from this trial also suggested a good protection of preterm born infants [17]. A study on immunogenicity of PCV7 from Italy in 46 preterm born infants showed antibody levels comparable to those in 46 full term infants [18]. However, another immunogenicity study from the UK with 68 preterm infants and 69 full term infants showed lower antibody levels among the preterm infants [19]. Furthermore, the lack of evidence of protection by PCV7 of preterm infants born before 32 weeks gestation from IPD has been stressed [20]. General vaccination with PCV7 of all infants was recommended in July 2006 in Germany. In this study we evaluate the impact of PCV7 on IPD in preterm born infants in Germany comparing children born in 2000 with those born in 2007.
C Biomed Central

C 2010 Rückinger et al; licensee BioMed Central Ltd. This is an Open Access article distributed under the terms of the Creative Commons Attribution License (http://creativecommons.org/licenses/by/2.0), which permits unrestricted use, distribution, and reproduction in any medium, provided the original work is properly cited. 


\section{Methods}

We report data from active prospective surveillance of IPD in all German pediatric hospitals. Hospitals were contacted on a monthly basis via postcards to ask if a case of invasive pneumococcal disease had been observed the last month. The case definition of IPD was isolation of Streptococcus pneumoniae from at least one culture of blood, cerebrospinal fluid, or a sample from any other normally sterile body site. Cases were excluded if they did not match the case definition, were older than 15 years, or double reports. Physicians filled comprehensive questionnaires on disease manifestation, outcome, vaccinations, and underlying conditions. There was a check box specifically asking for preterm birth and week of gestation of preterm births. Details of the study have been described elsewhere $[13,21,22]$. The study is part of the International Network of Paediatric Surveillance Units (INoPSU) [23].

Microbiologic laboratories were invited to send pneumococcal strains isolated from a normally sterile body site to the German National Reference Center for Streptococci, where the species identification was confirmed and serotyping, using Neufeld's Quellung method [24], was performed.

In order to account for a population denominator, the number of preterm born children (before 37 completed weeks gestation) was estimated based on the assumption that about $7 \%$ of children in Germany are born preterm. Based on the hospital surveillance, we compared data from two preterm birth cohorts: those born in 2000 and those born in 2007. Infants from both birth cohorts were under surveillance for at least one and two years at maximum: 2000-2001 and 2007-2008 respectively. Also based on the hospital surveillance we compared IPD notifications for all children (irrespective whether preterm born or not) for the birth cohorts of the years 2000 and 2007 using the same approach. Numbers on all births in Germany were provided by the Federal Statistical Office Germany. Incidence estimates were calculated based on IPD notifications from the respective (preterm) birth cohort reported in the year of birth and the subsequent year. These total numbers were divided by the respective number of (preterm) born children. Incidence estimates from 2000-2001 and 2007-2008 were compared using Fisher's exact test for difference in proportions.

Because this study is based on retrospective case analysis, without the possibility of identifying individual subjects, only data protection issues are of concern. Consent of the Bavarian data protection office was given.

\section{Results}

Between January 2007 and December 2008, 58 cases of IPD in children born in 2007 were reported from Germany pediatric hospitals compared to 115 cases in children born in 2000 reported between 2000 and 2001 (Table 1). This corresponds to a reduction in notifications per 100,000 from 15.0 to $8.5(P<.001)$. The reported number of preterm born children with IPD was 14 in 2000-2001 and 8 in 2007-2008. This corresponds to a reduction in notification rate from 26.1 to 16.7 per 100,000 comparing the 2000 with the 2007 preterm birth cohort $(P=.39)$. Among the 14 cases of IPD among preterm born children, 9 had information on serotype and for 7 of these the serotype was included in PCV7 (14 (3 cases), 18C (2 cases), 19A, 23F, 3, 9V).

Among the preterm born children born in 2000, 6 out of 14 had a gestational age of less than 32 weeks and one child had bronchopulmonary dysplasia. Among the preterm born children born in 2007, 3 out of 8 had a gestational age of less than 32 weeks and one child had partial trisomy 15 .

Characteristics of the eight IPD cases in children born preterm in 2007 reported between 2007 and 2008 are shown in Table 2. Five out of eight cases were born after the $32^{\text {nd }}$ week gestation. Four cases were vaccinated with PCV7 prior to disease onset. However no infant had received full vaccination with booster dose according to the recommended scheme. In two cases a serotype included in PCV7 was found. These two cases had not received pneumococcal vaccination prior to disease onset, although they were at an appropriate age. In two cases a neurological deficit was reported as outcome and in one case a cerebral parenchymal damage.

\section{Discussion}

Comparing the 2000 and 2007 birth cohorts we have observed a similar reduction in IPD notifications in preterm born children compared to children born at term after introduction of the general pneumoccal vaccination programme in Germany. These data suggest that PCV7 vaccination is similarly effective in protecting preterm born infants from IPD compared to full term children.

Our results add to previous evidence of protection of preterm born infants from IPD from a randomized controlled trial [17], and studies on immunogenicity of PCV7 in preterm infants $[18,19]$. In the randomized controlled trial 4,340 preterm born children were enrolled and none of these had IPD in the intervention group compared to 9 IPD cases in the control group. The about 2-fold higher IPD rates among preterm born children we observed are in line with the finding of a 1.6-fold increased risk of IPD in preterm born children from this clinical trial [17].

It is relatively unlikely that the reduction of IPD incidence among preterm born children was influenced by herd immunity. The vaccination program was not fully implemented before January 2007 and it was estimated 
Table 1 Births and preterm births in 2000 and 2007 in Germany and invasive pneumococcal disease (IPD) cases reported from these birth cohorts in 2000-2001 and 2007-2008 respectively.

\begin{tabular}{|c|c|c|c|c|}
\hline & \multicolumn{2}{|c|}{ Birth cohort } & \multirow[b]{2}{*}{ Percentage decrease } & \multirow[b]{2}{*}{$P^{\mathrm{a}}$} \\
\hline & 2000 & 2007 & & \\
\hline \multicolumn{5}{|l|}{ All infants: } \\
\hline Births & 766,999 & 684,862 & & \\
\hline IPD notifications & 115 & 58 & & \\
\hline IPD notifications per 100,000 & 15.0 & 8.5 & 43.3 & $<.001$ \\
\hline \multicolumn{5}{|l|}{ Preterm born infants: } \\
\hline Births $^{b}$ & 53,690 & 47,940 & & \\
\hline IPD notifications & 14 & 8 & & \\
\hline IPD notifications per 100,000 & 26.1 & 16.7 & 36.0 & .39 \\
\hline
\end{tabular}

a $P$ value calculated with Fisher's exact test.

${ }^{b}$ Estimated based on a prevalence of preterm birth of $7 \%$.

that less than $80 \%$ of all children born in 2007 were fully vaccinated [13]. Therefore, it is most likely that these results rather reflect direct protection of the vaccine.

The distribution of gestational age among preterm born children with IPD from the 2007 preterm birth cohort does not suggest that infants born before 32 weeks gestation are protected considerably less than infants born after 32 weeks gestation. However, case numbers and therefore statistical power may be too small for a conclusive answer and future studies on the effectiveness of PCV7 in very preterm born infants are needed.

Timing of vaccination in preterm infants born in 2007 was not in accordance with the German guidelines that advocate vaccination at $2,3,4$, and 11-14 months. Four cases had received no vaccination although they were at an appropriate age before disease onset. This confirms concerns about the tendency towards delayed immunization of preterm infants, exposing them for infection at time points where they are most vulnerable [15].

This study is somehow limited by the fact that the exact number of preterm born infants in Germany is unknown. There are complete surveys on births in some parts of Germany. Data from these surveys suggest that the proportion of preterm born infants was stable regarding the study period (personal communication by Dr. Lack, Bavarian Quality Assurance Institute for Medical Care, Munich, Germany). Another limitation is the lack of trend data, e.g. for the birth cohorts between 2001 and 2006. The hospital surveillance system was confined to vaccinated cases between 2003 and 2006. Furthermore, a recommendation to vaccinate preterm born children with PCV7 was issued in 2001. Therefore the 2000 birth cohort represents the only birth cohort for which data on unvaccinated preterm born children could be analysed.

\section{Conclusions}

In summary this study adds to evidence that PCV7 also protects preterm born infants from IPD and points to the need for timely vaccination of preterm children according to their chronological age as recommended e. g. by the German Standing Vaccination Committee (STIKO) and the American Academy of Pediatrics Committee on Infectious Diseases [25].

\section{Acknowledgements}

We thank all pediatricians who reported IPD cases. This study was supported by a grant from Wyeth.

Table 2 Characteristics of invasive pneumococcal disease (IPD) of preterm births born in 2007 from surveillance 20072008.

\begin{tabular}{|c|c|c|c|c|c|c|}
\hline ID & Sex & Gestational week & IPD at age (months) & PCV7 vaccination & Sequelae & Serotype \\
\hline 1 & M & 24 & 9 & 8 months & Neurological deficit & $15 B$ \\
\hline 2 & $\mathrm{~F}$ & 30 & 8 & - & Cerebral parenchymal damage & $23 \mathrm{Fa}$ \\
\hline 3 & M & 31 & 22 & 4,5 , and 7 months & - & Unknown \\
\hline 4 & $\mathrm{~F}$ & 35 & 20 & - & Unclear & $14 a$ \\
\hline 5 & $\mathrm{~F}$ & 36 & 9 & 3 and 4 months & - & $10 \mathrm{~A}$ \\
\hline 6 & $\mathrm{~F}$ & 36 & 3 & - & - & Unknown \\
\hline 7 & M & 36 & 6 & - & - & Unknown \\
\hline 8 & M & 37 & 5 & 4 months & Neurological deficit & $19 A$ \\
\hline
\end{tabular}

\footnotetext{
${ }^{a}$ Serotype included in PCV7.
} 


\section{Author details}

'Ludwig-Maximilians-University of Munich, Institute of Social Pediatrics and Adolescent Medicine, Division of Epidemiology, Germany. ${ }^{2}$ National Reference Center for Streptococci, Institute of Medical Microbiology, University Hospital RWTH Aachen, Germany.

\section{Authors' contributions}

SR suggested the idea for the article, performed the statistical analysis and wrote the manuscript. MvdL contributed to the writing of the manuscript and revised the final version for important intellectual content. RvK supervised the writing of the manuscript and revised the final version of the manuscript for important intellectual content.

\section{Competing interests}

RvK and MvdL have received grant support from Wyeth

Received: 14 September 2009

Accepted: 19 January 2010 Published: 19 January 2010

\section{References}

1. O'Brien KL, Wolfson LJ, Watt JP, Henkle E, Deloria-Knoll M, McCall N, Lee E, Mulholland K, Levine OS, Cherian T: Burden of disease caused by Streptococcus pneumoniae in children younger than 5 years: global estimates. Lancet 2009, 374:893-902.

2. de Bedford H, Louvois J, Halket S, Peckham C, Hurley R, Harvey D: Meningitis in infancy in England and Wales: follow up at age 5 years. Bmj 2001, 323:533-536.

3. Davidson M, Schraer CD, Parkinson AJ, Campbell JF, Facklam RR, Wainwright RB, Lanier AP, Heyward WL: Invasive pneumococcal disease in an Alaska native population, 1980 through 1986. Jama 1989, 261:715-718.

4. Haddy RI, Perry K, Chacko CE, Helton WB, Bowling MG, Looney SW, Buck GE: Comparison of incidence of invasive Streptococcus pneumoniae disease among children before and after introduction of conjugated pneumococcal vaccine. Pediatr Infect Dis J 2005, 24:320-323.

5. Rendi-Wagner P, Georgopoulos A, Kundi M, Mutz I, Mattauch M, Nowak J, Mikolasek A, Vecsei A, Kollaritsch H: Prospective surveillance of incidence, serotypes and antimicrobial susceptibility of invasive Streptococcus pneumoniae among hospitalized children in Austria. J Antimicrob Chemother 2004, 53:826-831.

6. Syriopoulou V, Daikos GL, Soulis K, Michos A, Alexandrou H, Pavlopoulou I, Pagali IPA, Hadjichristodoulou C, Theodoridou M: Epidemiology of invasive childhood pneumococcal infections in Greece. Acta Paediatr Suppl 2000, 89:30-34.

7. Centers for Disease Control and Prevention (CDC): Direct and indirect effects of routine vaccination of children with 7-valent pneumococcal conjugate vaccine on incidence of invasive pneumococcal diseaseUnited States, 1998-2003. MMWR Morb Mortal Wkly Rep 2005, 54:893-897.

8. Centers for Disease Control and Prevention (CDC): Invasive Pneumococcal Disease in Children 5 Years After Conjugate Vaccine Introduction Eight States, 1998-2005. MMWR Morb Mortal Wkly Rep 2008, 57:144-148.

9. Black S, France EK, Isaacman D, Bracken L, Lewis E, Hansen J, Fireman B, Austrian R, Graepel J, Gray S, Klein NP: Surveillance for invasive pneumococcal disease during 2000-2005 in a population of children who received 7-valent pneumococcal conjugate vaccine. Pediatr Infect Dis J 2007, 26:771-777.

10. Kyaw MH, Lynfield R, Schaffner W, Craig AS, Hadler J, Reingold A, Thomas AR, Harrison LH, Bennett NM, Farley MM, et al: Effect of introduction of the pneumococcal conjugate vaccine on drug-resistant Streptococcus pneumoniae. N Engl J Med 2006, 354:1455-1463.

11. Whitney CG, Farley MM, Hadler J, Harrison LH, Bennett NM, Lynfield R, Reingold A, Cieslak PR, Pilishvili T, Jackson D, et al: Decline in invasive pneumococcal disease after the introduction of protein-polysaccharide conjugate vaccine. N Engl J Med 2003, 348:1737-1746.

12. Rose M, Zielen S: Impact of infant immunization programs with pneumococcal conjugate vaccine in Europe. Expert Rev Vaccines 2009, 8:1351-1364.

13. Rückinger $S$, Linden van der $M$, Reinert RR, von Kries $R$, Burckhardt $F$, Siedler A: Reduction in the incidence of invasive pneumococcal disease after general vaccination with 7-valent pneumococcal conjugate vaccine in Germany. Vaccine 2009, 27:4136-4141.
14. Hjuler T, Wohlfahrt J, Simonsen J, Kaltoft MS, Koch A, Kamper-Jorgensen M, Biggar RJ, Melbye M: Perinatal and crowding-related risk factors for invasive pneumococcal disease in infants and young children: a population-based case-control study. Clin Infect Dis 2007, 44:1051-1056

15. Langkamp DL, Hoshaw-Woodard S, Boye ME, Lemeshow S: Delays in receipt of immunizations in low-birth-weight children: a nationally representative sample. Arch Pediatr Adolesc Med 2001, 155:167-172.

16. Black S, Shinefield H, Fireman B, Lewis E, Ray P, Hansen JR, Elvin L, Ensor KM, Hackell J, Siber G, et al: Efficacy, safety and immunogenicity of heptavalent pneumococcal conjugate vaccine in children. Northern California Kaiser Permanente Vaccine Study Center Group. Pediatr Infect Dis J 2000, 19:187-195.

17. Shinefield H, Black S, Ray P, Fireman B, Schwalbe J, Lewis E: Efficacy, immunogenicity and safety of heptavalent pneumococcal conjugate vaccine in low birth weight and preterm infants. Pediatr Infect Dis J 2002 , 21:182-186.

18. Esposito S, Pugni L, Bosis S, Proto A, Cesati L, Bianchi C, Cimino C, Mosca F, Principi N: Immunogenicity, safety and tolerability of heptavalent pneumococcal conjugate vaccine administered at 3,5 and 11 months post-natally to pre- and full-term infants. Vaccine 2005, 23:1703-1708.

19. Ruggeberg JU, Collins C, Clarke P, Johnson N, Sinha R, Everest N, Chang J, Stanford $E$, Balmer $P$, Borrow $R$, et al: Immunogenicity and induction of immunological memory of the heptavalent pneumococcal conjugate vaccine in preterm UK infants. Vaccine 2007, 25:264-271.

20. D'Angio CT: Active immunization of premature and low birth-weight infants: a review of immunogenicity, efficacy, and tolerability. Paediatr Drugs 2007, 9:17-32.

21. Von Kries R, Heinrich B, Hermann M: Pädiatrische Epidemiologie in Deutschland: Forschungsinstrument ESPED (Erhebungseinheit für seltene pädiatrische Erkrankungen in Deutschland). Monatsschrift Kinderheilkunde 2001, 149:1191-1197.

22. von Kries R, Siedler A, Schmitt HJ, Reinert RR: Proportion of invasive pneumococcal infections in German children preventable by pneumococcal conjugate vaccines. Clin Infect Dis 2000, 31:482-487.

23. Grenier D, Elliott EJ, Zurynski Y, Rodrigues Pereira R, Preece M, Lynn R, von Kries R, Zimmermann H, Dickson NP, Virella D: Beyond counting cases: public health impacts of national Paediatric Surveillance Units. Arch Dis Child 2007, 92:527-533.

24. Neufeld F: über die Agglutination der Pneumokokken und über die Theorie der Agglutination. Zeitschrift für Hygiene und Infektionskrankheiten 1902, 40:54-72.

25. American Academy of Pediatrics: Immunization in special clinical circumstances. Red Book: Report of the Committee on Infectious Diseases IL: American Academy of PediatricsPeter G, Elk Grove Village, IL , 24 1997, 48.

\section{Pre-publication history}

The pre-publication history for this paper can be accessed here:http://www. biomedcentral.com/1471-2334/10/12/prepub

doi:10.1186/1471-2334-10-12

Cite this article as: Rückinger et al.: Effect of heptavalent pneumococcal conjugate vaccination on invasive pneumococcal disease in preterm born infants. BMC Infectious Diseases 2010 10:12

\section{Submit your next manuscript to BioMed Central and take full advantage of:}

- Convenient online submission

- Thorough peer review

- No space constraints or color figure charges

- Immediate publication on acceptance

- Inclusion in PubMed, CAS, Scopus and Google Scholar

- Research which is freely available for redistribution 